\title{
LAS FUERZAS SINDICALES Y LA CONSTITUCION
}

Por PABLO LUCAS MURILLO Universidad Autónoma de Madrid

\section{LAS FUERZAS POLITICAS Y LA CONSTITUCION}

Las fuerzas políticas pueden considerarse como configuradoras efectivas del Estado contemporáneo. Su función esencial de agentes de la dinámica política, realizando e impulsando los procesos políticos que permiten la pervivencia de la vida social, así lo corrobora. En efecto, contribuyen a la creación de los cuadros institucionales y de las formas políticas que deben encauzar el proceso de orientación política en el que, a su vez, participan. Por otra parte, condicionan la virtualidad de los elementos organizativos o estáticos de las estructuras políticas en la medida que éstos sólo podrán canalizar los procesos de la dinámica política si responden al equilibrio de las fuerzas político-sociales que se realiza en la sociedad.

Es, pues, evidente que no se puede prescindir de ellas a la hora de estudiar los problemas constitucionales, ya que son estas fuerzas las que dan vida y hacen funcionar los mecanismos institucionales que predispone el ordenamiento fundamental del Estado. La funcionalidad y eficacia de las estructuras estatales depende de la mediación que los grupos políticos-sociales realizan entre el mundo real, el político y el jurídico, es decir, de la

(*) El presente trabajo constituye la ponencia presentada en las IV Jornadas Internacionales de Ciencia Política y Derecho Constitucional celebradas en Valencia los días del 4 al 7 de octubre de 1978. 
efectiva asunción por parte del Estado de los requerimientos que se le formulan desde la sociedad (1).

Siendo esto así, no es de extrañar que se prefiera acudir, para clasificar los sistemas de gobierno, a la consideración del sistema de partidos que subyace a las instituciones constitucionales (2).

El constitucionalismo de la posguerra es consciente de cuanto acabamos de señalar. Por eso, no duda en reconocer el carácter pluralista de la sociedad contemporánea (así el artículo $2 .^{\circ}$ de la Constitución italiana, el artículo $1 .^{\circ}$ del Proyecto español -también los artículos 6 y 7-; el artículo $2 .^{\circ}$ de la Constitución portuguesa de 1976) y el papel fundamental que las formaciones sociales intermedias -entre las cuales se han de situar las fuerzas políticas- realizan al constituir el puente que comunica el individuo con las instancias del aparato estatal.

Así, la constitucionalización de los partidos políticos, de los sindicatos y de otros grupos es una de las características más acusadas del Estado social de Derecho. Se trata de un proceso político que coincide con el de la institucionalización política en la medida que trata de acomodar las estructuras organizativas estatales a la evolución social, para superar la separación estado-sociedad, típica del Estado liberal. Favorece el ascenso de la comunidad al aparato autoritario. De este modo, el Derecho no vive a espaldas de la realidad cotidiana.

Las consideraciones precedentes justifican, portanto, que fijemos nuestra atención en las fuerzas políticas a la hora de estudiar los problemas que pueden plantearse en el funcionamiento del sistema de gobierno que establece la Constitución española. En concreto, nos interesa contemplar la incidencia que puede tener la acción sindical sobre la relación GobiernoCongreso de los Diputados.

\section{El sindicato como fuerza política}

Puede parecer extraño que traigamos a colación a los sindicatos con referencia al mecanismo mediante el cual se determina la política general del Estado.

(1) Cfr. Temistocle Martines, Contributo ad una teoria giuridica delle forze politiche. Giuffrè, Milán, 1957, págs. 312-313. En definitiva, al hacer estas afirmaciones somos consecuentes con aquella postura metodológica que propugna la necesidad de complementar —en el estudio del Derecho Político- el dato normativo-institucional con el científico-político. Véase, al respecto, Pablo Lucas Verdú: Curso de Derecho Político, vol. I. Tecnos, Madrid, 1972, págs. 28 y sigs.

(2) Maurice Duverger, Los partidos políticos (traducción especial de Julieta Campos y Enrique González Pedrero). Fondo de Cultura Económica. México, 1965, págs. 418-420. 
En efecto, a menudo se insiste en el carácter apolítico, profesional, económico que lleva implícito el concepto de sindicato. Se dice que su finalidad consiste en la mejora de las condiciones de trabajo y que, en consecuencia, su esfera de acción se ha de limitar a la empresa. Todo lo que salga de este marco constituye una injerencia en un campo que al parecer le está vedado (3).

En realidad, lo que ocurre es que cuando se hacen estas afirmaciones en muchos casos no se pretende otra cosa que marcar las diferencias con respecto a los partidos políticos, bien para recalcar la necesaria autonomía de unos y otros, bien para subrayar sus distintos modos de actuar. En otras ocasiones, se trata de una excusa para reprimir la acción sindical cuando ésta se dirige a la lucha por la instauración de un régimen político opuesto al establecido. De este último supuesto, la historia reciente de nuestro país nos ofrece ejemplos significativos.

Aún teniendo en cuenta la dificultad que supone el concepto (4), podemos distinguir dos tipos de fuerzas políticas: aquellas de las que se dice que son políticas, ya que pretenden posesionarse del poder estatal para desde él actuar sus programas - los partidos políticos - y las formaciones sociales que tienen fuerza política (5) -así los grupos de presión, los sindicatos...- en cuanto que disponen de medios para presionar a las instancias estatales, o para contribuir a la determinación de la política general. Cuando se admite el carácter de fuerza política de los sindicatos se les suele incluir dentro de la categoría conceptual de los grupos de presión (6). No obstante, preferimos conceptuarlos autónomamente. Cierto que presenta numerosos rasgos comunes con éstos, pero, junto a ellos,

(3) Cfr. al respecto, José Antonio Ezcurdia, El sindicalismo político. Razón y Fe. Madrid, 1966, págs. 48 y sigs.

(4) Georges Burdeau, Traité de Science Politique, t. III. La dynamique politique. LGDJ. París, 1968 (12. a ed. rev. y aum.), pág. 16.

(5) Juan Ferrando Badía, «La vida política democrática: sus factores», en Revista de Estudios Sociales. Madrid, enero-abril 1973, pág. 81. Asimismo, Martines, op. cit., pág. 149. También se puede llegar a la misma conclusión en base a las consideraciones que formula Burdeau, op. cit., págs. 14 y sigs.

(6) Jean Meynaud, Les groupes de pression. Presses Universitaires de France, París. 1962. Fntre nosotros. Luis Sánchez Agesta. Principios de Teoria Política. Editora Nacional. Madrid, $1976\left(6 .^{\mathrm{a}}\right.$ ed. rev.), págs. 241-242. Creemos que no es ésta la ocasión para detenernos sobre el concepto y caracteres de los grupos de presión. Cfr., además de las obras que acabamos de señalar, Juan Ferrando Badía, «Grupos de interés, de promoción y de presión. Institucionalización de los grupos de presión», en la Revista de Estudios Políticos, núms. 213-214. Madrid, mayo-agosto 1977, págs. 9-44; Pablo Lucas Verdú, Principios de

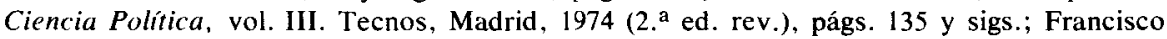
Murillo Ferrol, Estudios de Sociología Política. Tecnos, Madrid, 1963, págs. 343-365. 
encontramos otros que les diferencian de un modo ostensible. No se trata solamente de señalar el gran poder del que pueden disponer para actuar en relación con los Poderes públicos por medio de la movilización de la opinión pública, o por su capacidad subversiva si actúan como instrumentos de una acción revolucionaria (7), sino que para los fines que nos proponemos nos interesan más los aspectos que señalamos a continuación:

a) El poder normativo de que disponen los sindicatos en cuanto sujetos - junto a las organizaciones empresariales- de la contratación colectiva.

b) La necesidad de su cooperación para llevar a buen fin cualquier política socio-económica gubernamental. Recordemos que Meynaud, al hablar de los límites que afectan a la elaboración de la política económica, señala la posición, al respecto, de las fuerzas sociales y, en concreto, de los sindicatos (8).

c) La atribución a los mismos del derecho de huelga.

d) La creciente tendencia de los trabajadores a sindicarse y su concentración en un número reducido de sindicatos que, en algunos casos, se confederan entre sí, como ocurre en Italia.

e) Su actuación delante de la opinión pública de un modo descubierto.

f) Su institucionalización jurídico-constitucional (9).

g) Asimismo, contribuye a otorgar entidad propia a los sindicatos el hecho de que «desde su aparición han sido organizaciones de defensa de intereses inmediatos y movimientos sociales orientados hacia la transformación o hacia el mantenimiento y mejora de una estructura política» (10). La componente ideológica de los mismos

(7) Giovanni Sartori, «Il potere del lavoro nella società post-pacificata: «Un futuribile sindacale», en Quaderni della Rivista Italiana di Scienza Politica. Il Mulino, Bolonia, 1976, págs. 77-127, se refiere a la posibilidad de que un sindicato de técnicos en informática pueda controlar el Estado dada la importancia, mayor cada día, de las computadoras en la organización de la vida social. Sobre los instrumentos de la acción sindical frente a los poderes del Estado, cfr. Ibidem, Samuel E. Finer: «I sindacati e lo Stato-liberal-democratico», págs. 51. 75.

(8) Jean Meynaud, La elaboración de la política económica (trad. esp. de Jorge Petit Fontseré). Tecnos, Madrid, 1969 (reimp.), págs. 182-183.

(9) Enrico Spagna Musso, Diritto constituzionale. Cedam, Padua, 1976, págs. 170-171, señala que: la problematica constituzionale del gruppo di pressione $\grave{e}$, invece, diversa in quanto esso non constituisce di per se una instituzione giuridica (come si verifica per il partido ed il sindacato).

(10) Manuel García Pelayo, Las transformaciones del Estado contemporáneo. Alianza Editorial, Madrid, 1977, págs. 78-79. Asimismo, Burdeau, Traité..., t. VIII. La démocratie et les contraintes du nouvel Age. LGDJ. París, 1974 (12.ª ed.), pág. 138; Umberto Romagnoli, "Sindacati», en el Dizionario di Politica diretto da Norbeto Bobbio e Nicola Matteuci. UTRT, Turín, 1976, pág. 921. 
explica este doble aspecto. Como toda fuerza política realizan una valoración de sus intereses, necesidades y aspiraciones conforme a una concepción del mundo y de las relaciones sociales que, generalmente se basa en las doctrinas socialistas y, dentro de ellas, en el socialismo científico es decir, en el marxismo.

Ante estos datos, pensamos que considerar grupo de presión al sindicato es demasido forzado. Si se incluye en esa categoría conceptual, inmediatamente habrá que hacer sobre el mismo tal número de precisiones que lo excepcional resultará ser su carácter de grupo de presión y la regla todo lo que escapa a esa figura. Por eso, preferimos darle un lugar propio entre las fuerzas político-sociales (11).

\section{EL TRATAMIENTO CONSTITUCIONAL DE LOS SINDICATOS}

Pasando a ocuparnos de la relación sindicatos-sistema de gobierno en el contexto de la Constitución, comenzaremos examinando brevemente la regulación constitucional que el legislador ha dispuesto para estas fuerzas políticas. No es nuestra intención realizar un estudio completo de los distintos preceptos relativos a los sindicatos, pues superaría los límites de nuestra intervención.

En primer lugar, importa destacar el hecho de que se dedique un artículo del título preliminar (art. $7 .^{\circ}$ ) a los sindicatos de trabajadores junto con las asociaciones empresariales. Teniendo en cuenta que el título preliminar contiene la fórmula política de la Constitución $(12$, el conjunto de principios e instituciones que inspiran todo el texto constitucional y suponen el núcleo considerado esencial por las fuerzas políticas que han dado vida al presente texto fundamental, es evidente la importancia que así se atribuye a los sindicatos.

En efecto, se les concibe como elementos imprescindibles del régimen político que se instaura, una expresión del pluralismo de nuestra sociedad, tutelado con la rigidez reforzada que prescribe el artículo 168.

Por otra parte, la referencia a su actividad de promoción de sus intereses peculiares, al mismo tiempo que se afirma otro tanto con relación a las asociaciones empresariales, parece significar el reconocimiento constitucio-

(11) Burdeau, op, ult. cit., pág. 292; Sartori, op. cit., págs. 102-104.

(12) Lucas Verdú, Curso... cit., págs. 368 y sigs. El concepto de fórmula política se corresponde con el de Constitución material elaborado por la doctrina italiana. Cfr. Costantino Mortari, Istituzioni di Diritto Pubblico, vol. I. Cedam, Padua, 1975 (9. a ed.), págs. 30-31. 
nal de la realidad del conflicto de clases si se pone en relación con el artículo $9 .^{\circ}-2$.

De los artículos $7 .^{\circ}-28,35-2,37$ y 131-2 resulta que la Constitución entiende los sindicatos como instituciones del Estado, comunidad que en un marco de libertad (artículos $70^{\circ}$ y $28-1$ ) han de desempeñar un papel fundamental en la regulación de las condiciones de trabajo a través de la contratación colectiva (art. 37-1) y en la promoción de la condición de los trabajadores por medio del derecho de huelga, que si bien no se les reconoce a ellos directamente, sino a los trabajadores, es evidente que al consistir en la abstención colectiva del trabajo será conducida por los sindicatos (arts. 28-2 y 37-2).

Por último, digamos que, además del mandato dirigido al legislador para que emane un estatuto de los trabajadores (art. 35-2) que, sin duda, vendrá a reforzar, aún más, las posibilidades sindicales para la defensa de la clase trabajadora, hay que referirse a la introducción de un Consejo Económico que, integrado por sindicatos, organizaciones profesionales empresariales y económicos ha de asesorar y colaborar con el gobierno en la elaboración de los proyectos de planificación (art. 131-2).

De todo este conjunto de disposiciones conviene subrayar: 1. Las limitaciones que se establecen para los funcionarios y la posibilidad de que se suprima el derecho de sindicación para las fuerzas armadas y los cuerpos armados sometidos a disciplina militar (art. 28-1); 2 . Restricciones que se manifiestan, a su vez, en cuanto al derecho de huelga (arts. 28-2 y 37-2) y contrastan con 3. la constitucionalización del Lock Out (art. 37-2) que para nosotros no es admisible tras una declaración como la que efectúa el artículo $90^{\circ}-2$.

A la vista del texto constitucional en lo relativo a la concepción sindical, no apreciamos grandes novedades - entendidas en el sentido de superación de los modelos existentes en otras democracias pluralistas- y, en principio, parece cerrar a las asociaciones sindicales el acceso a los centros de decisión política, si se excluye la referencia a su participación en el Consejo económico sobre cuya virtualidad, por otra parte, pueden plantearse ya serias dudas ante la experiencia verificada al respecto en otros países (13).

(13) Cfr. Burdeau, Traité... t. VII. La démocratie gouvernante. LGDJ. París, 1972 (12. a ed. rev. y aum.), págs. 371-374; Carl J. Friedrich, Gobierno Constitucional y Democracia (trad. esp. de Agustín Gil Lasierra). Instituto de Estudios Políticos. Madrid, 1975, vol. II, págs. 413-414; García Pelayo. op. cit., pág. 123. Véase también sobre el tema Jorge De Esteban, «La representación de intereses y su institucionalización», en Revista de Estudios Políticos, núm. 155. Madrid, septiembre-octubre 1976, págs. 59 y sigs. 
Sin embargo, no es difícil descubrir en las formas típicas de la acción sindical que han sido recogidas en los artículos 28 y 37 caracteres que suponen un poder político y que, en consecuencia, permiten su utilización para concurrir a la adopción de las decisiones de gobierno (14). Se ha de pensar, además, si esta capacidad sindical que nos encontramos en la realidad no esté justificada en base al artículo $90^{\circ}-2$ en la medida que:

1. Atribuye a todos los españoles el derecho a participar en la vida política, cultural y social.

2. Reconoce que las condiciones socioeconómicas actuales no permiten la plena vigencia de los principios de libertad e igualdad y, por tanto, tampoco una verdadera participación político-social. En este sentido, y teniendo presente que la situación que describe este artículo es la de la clase trabajadora - aunque no se haya querido transcribir, al igual que el resto, la palabra trabajadores, del modelo italiano-, podría mantenerse que la contratación colectiva y el derecho de huelga han de ser instrumentalizados tanto hacia el avance hacia una igualdad sustancial como hacia una plena participación. De este modo se plantea el problema de armonizar esta función política sindical con el mecanismo constitucional de determinación de la orientación política nacional.

Ahora bien, ¿en qué medida pueden encerrar los convenios colectivos de trabajo un poder de dirección política? Ciertamente el fin inmediato que se persigue con ellos es de naturaleza juridico-económica: la disciplina de la relación laboral. No obstante, en cuanto concurren algunas circunstancias como la extensión de su ámbito de eficacia a niveles provinciales o incluso nacionales, cuando se acuerdan en ellos aspectos relativos a la organización del trabajo y de la producción, si se tiene en cuenta, además, la fuerza vinculante que otorga a la negociación colectiva el artículo 33-1, habrá que convenir en la importancia que puede tener este poder normativo si se utiliza — como puede darse el caso- para perseguir fines de transformación social.

Basta pensar, por ejemplo, en el número de empresas (564.056) y de trabajadores (2.173.161) afectados por los 265 convenios colectivos que

(14) Cfr. Segio Fois, Sindacati e sistema politico: problematica di un rapporto e implicazioni costituzionali. Giuffrè, Milán, 1977, págs. 20 y sigs. Ahora en Scritti in onore di Costantino Mortati, vol. III. Giuffrè. Milán, 1977, págs. 416 y sigs.; Martines, op. cit., págs. 217-218. 
debían renovarse en el último trimestre del año 1978 (15) y la situación que se produciría si los sindicatos hubieran aprovechado la ocasión para desencadenar un período de conflictividad social para obtener del gobierno una determinada política económica.

Por lo que hace referencia al derecho de huelga, la cuestión es aún más evidente. Y ello aunque los términos y las cautelas de los artículos $28-2$ y 37-2 circunscriben este medio de autotutela a la defensa de los «intereses» de los trabajadores y se encomiende a la ley reguladora del ejercicio de este derecho garantizar el mantenimiento de los servicios esenciales de la comunidad. Tras la dicción de los artículos citados parece encerrarse el intento de circunscribir la huelga al marco de la contratación colectiva excluyendo la llamada huelga política y dificultando la de solidaridad.

Del mismo modo que los contratos colectivos tienen una indudable vertiente política, la huelga realizada en el contexto de los mismos también la presenta y, además, con una intensidad mayor, puesto que no sólo se limita a recoger los contenidos de la negociación, sino que, además, los afirma con la adopción de una postura de fuerza. Sin embargo, lo que otorga a la huelga un especial relieve desde el punto de vista político es la posibilidad de realizarla en el ámbito extracontractual.

El derecho de huelga que reconoce el artículo 28-2 $i$ ha de ejercerse dentro de la negociación colectiva a que alude el artículo 37-1? Nosotros no vemos que tal relación, no producida históricamente (16), se desprenda del texto constitucional. Por otra parte, los intereses de los trabajadores no se limitan, como es obvio, al contrato colectivo, ya que éste debe ceñirse a lo que viene dispuesto por las directrices de política económica emanadas por el Gobierno. Pensamos que la precisión de cuáles sean los intereses de los trabajadores debe hacerse más que sobre la base del artículo 37-1, en consonancia con el artículo 9.9-2. Además, empeñarse en restringir el derecho de huelga en base al criterio de la exclusión del carácter político no conducirá a otra cosa que convertir el texto constitucional que se tome como fundamento en letra muerta porque la huelga extracontractual se dará en la realidad.

Con todo, no es aventurado afirmar que éste será un problema a resolver por la jurisprudencia del Tribunal Constitucional, tal como ha sucedido en Italia, donde, tras una evolución progresiva, la Corte Constituzionale en su sentencia número 290 , de 27 de diciembre de 1974, vino a

(15) Tomo los datos de El País, Madrid, 20 de septiembre de 1978, pág. 41.

(16) Cfr. Constantino Mortati, «Il lavoro nella Constituzione», en Raccolta di scritti, vol. III. Giuffrè, Milán, 1972, pág. 332. 
admitir la constitucionalidad de la huelga política siempre que «no se dirija a subvertir el ordenamiento constitucional ni a obstaculizar el libre ejercicio de los poderes legítimos que expresan la soberanía popular» (17).

Dada la semejanza que presentan ambos textos constitucionales y la relativa similitud de la estructura social de ambos países (18), pensamos que la argumentación que ha conducido a la sentencia número 290 en Italia puede ser desarrollada en nuestro país. La existencia en ambos ordenamientos del fundamental artículo $9 .^{\circ}-2$ (Constitución española) y $3 .^{\circ}-2$ (Constitución italiana) facilitará esta solución.

No es necesario que nos extendamos aquí en subrayar la virtualidad política que supone el ejercicio del derecho de huelga, pues es evidente la coerción que implica, tanto frente a la parte empresarial como frente al Gobierno, cuando es proclamada o simplemente se amenaza con su proclamación por parte de los sindicatos más poderosos. Y ello, sin necesidad de que se trate de huelgas salvajes, puesto que también se puede hablar de madurez y responsabilidad de los sindicatos, que son conscientes de que ante una crisis económica son los trabajadores los más perjudicados.

\section{INCIDENCIA DE LA ACCION SINDICAL SOBRE EL SISTEMA DE GOBIERNO}

El sistema de gobierno que configura el texto constitucional corresponde al parlamentarismo racionalizado típico de las democracias occidentales tras la primera guerra mundial y consolidado, con posterioridad a la segunda conflagración.

Conforme al artículo 97, el Gobierno, bajo la dirección de su Presidente (art. 98-2), conduce la política y la administración del Estado. En el sistema establecido por la Constitución de 1978, la orientación de la política nacional que lleva a cabo el Gobierno viene determinada por una es-

(17) Advirtamos que ese mismo año, con la sentencia número 1 , de 14 de enero, la Corte admitía como conforme a la Constitución la huelga que se dirigiese a perseguir «intereses económicos de los trabajadores de orden general, derivables del título III de la Constitución -relativo a los derechos económicos. Cfr. Paolo De Carli, Constituzione e attività economiche. Cedam, Padua, 1978, págs. 110-111. Sobre la problemática del derecho de huelga en Italia, cfr. AA. VV. Lo sciopero dalla Constituzione all' autadisciplina. Quaderni del Cress. Il Mulino, Bolonia, 1975.

(18) Juan José Linz, El sistema de partidos en España. Narcea, S. A. de Ediciones, Madrid, 1976, págs. 21-22, alega estas semejanzas para aventurar la futura configuración del sistema partidista español si el electorado hispano se hubiese comportado como el italiano. 
tructura compleja de decisiones (19). En primer lugar, por la Constitución misma que marca las pautas conforme a las cuales ha de discurrir la vida estatal. Sobre la base de las coordenadas constitucionales los partidos elaboran sus diferentes interpretaciones ideológicas de los objetivos a conseguir por los órganos del Estado-aparato, y el cuerpo electoral, a través del sufragio, decide aquélla o aquéllas que han de realizarse.

En efecto, el voto determina la composición del Parlamento, y en función de ésta, el Rey propondrá un candidato a la Presidencia del Gobierno que recibirá la investidura como tal si tras la exposición de su programa recibe la confianza del Congreso de los Diputados (art. 99). El sistema se basa, por tanto, en una relación de confianza entre el Congreso y el Gobierno. En consecuencia, este último deberá contar con el apoyo de la mayoría de los diputados, que serán quienes deban aprobar el programa gubernamental.

¿Dónde situar a los sindicatos en este esquema que acabamos de exponer sumariamente?

Como hemos señalado con anterioridad, son fuerzas políticas dotadas de medios suficientes para influir en la vida del Estado y desestabilizarla si llegan a proponérselo.

No obstante, en situaciones de normal funcionamiento de las instituciones, su participación en la determinación de la orientación política puede tener lugar por medio de los instrumentos típicos sindicales cuales son los contratos colectivos y la huelga, siempre que se mantengan dentro del respeto al orden constitucional y no pretendan impedir el funcionamiento de los poderes estatales, tal y como señala la jurisprudencia constitucional italiana.

Además, ha de tenerse en cuenta que en tanto que agentes de la dinámica política entran en contacto con los partidos políticos, interaccionándose e influyéndose recíprocamente en cuanto que unos y otros están interesados en la política gubernamental. Lo que varía es sus distintos medios de actuar en relación con aquélla. En el caso español, la interacción partidos-sindicatos, por lo que se refiere a las centrales mayoritarias, se caracteriza por la estrecha vinculación entre el PSOE y la UGT y entre el PCE y las CC. OO., si bien todos se cuiden de afirmar su respectiva autonomía. No obstante, esta íntima relación produce la presencia de șindicalistas en los grupos parlamentarios socialistas y comunistas y la acumulación en las mismas personas de secretarías en las ejecutivas partidistas y sindicales.

(19) Cfr. Andrea Manzella, Il Parlamento. Il Mulino, Bolonia, 1977, págs. 284 y sigs. 
Si se tiene presente, por otra parte, la posibilidad que existe de la participación sindical en diferentes comisiones administrativas (así, por ejemplo, en materia de precios, de seguridad social, formación profesional, etc. (arts. 105-a) y 129-1 de la Constitución) su acceso a comisiones parlamentarias, en las audiencias que éstas pueden dedicar a las asociaciones sindicales y en otras posibles formas de intervención en la actividad del Estado — como la planificación según el artículo 131-2 - se puede llegar a una situación en la que el sindicato se integre en las estructuras políticas derivadas de la Constitución contribuyendo a la reducción, a términos jurídicos, de la conflictividad social.

Ahora bien, esta idílica imagen puede quebrarse. Toda la construcción constitucional puede quedar en entredicho si los mecanismos previstos no realizan la misión que se espera de ellos. Refiriéndonos concretamente al Parlamento - uno de los centros básicos— hay que decir que en la medida en que es contemplado como la principal sede de mediación entre los diversos intereses sociales que se agitan en el seno de la sociedad, ha de estar en relación constante con la realidad, en contacto directo con los ciudadanos que han delegado su representación en los parlamentarios. Asimismo, exige que los partidos políticos asuman sus funciones institucionales como partidos de gobierno o de oposición.

Si esto no es así, y se desvanecen los contornos entre unos y otros y la alternación en el Poder o no se produce o carece de relevancia por la homogeneidad de las distintas opciones, se puede producir una fragmentación del sistema partidista o el recurso a otras vías de participación política. La existencia de alternativas políticas y su sucesión en los Gobiernos se revelan como factores de estabilidad en los sistemas políticos. En cambio, la falta de diferenciación entre el partido en el Ploder y el partido de oposición, determina la incapacidad de ésta para absorber la protesta social que cada día, en las actuales condiciones económicas, se dirige, con mayor intensidad, al Estado «asistencial» (20).

Consecuencias parecidas suscita el secuestro de la política para la mayor parte de los ciudadanos. La superación del Parlamento como sede del debate político y su sustitución por los acuerdos políticos extraparlamentarios, por pactos entre los estados mayores de los principales partidos puede producir la búsqueda de cauces más eficaces para participar en la vida política y social y para luchar por los intereses concretos que preocu-

(20) Cfr. La investigación realizada por Steven B. Wolinetz, «Stabilità e mutamento nei sistemi partitici dell'Europa occidentale», en Rivista Italiana di Scienza Politica. Il Mulino, Bolonia, 1978 (n. ${ }^{\circ}$ 1), págs. 41 y sigs. 
pan a cada uno. En este sentido se ha señalado cómo la falta de funcionalidad y eficacia de los partidos políticos determinan el auge sindical y su creciente participación en la vida política nacional (21). Surge, así, el fenómeno del pansindicalismo, de la suplencia sindical (22), el intento sindical de sustituir a los partidos, la potenciación del instrumento de la huelga, que ha de considerarse como última ratio, la exasperación de la conflictividad social y la inestabilidad consiguiente de la vida política.

Evidentemente no son éstas las condiciones que se dan en nuestro país en la actualidad y los sindicatos españoles no parecen tentados por semejantes posibilidades. Sin embargo, es conveniente tener en cuenta la experiencia de otros países, sacar de ella las conclusiones necesarias para evitar errores ajenos y beneficiarse de los aciertos. La situación que acabamos de describir se ha presentado en Italia en los últimos tiempos y, sin embargo, en los años de la reconstrucción, tras el fin de la segunda guerra mundial, no era previsible este desarrollo, ni tampoco se podía prever en los años 50 cuando los sindicatos, en concreto la CGIL, eran una auténtica correa de transmisión de los partidos, que pudieran llegar a formulaciones de autonomía sindical como las que contemplamos hoy.

En consecuencia, para que nuestro texto constitucional nos depare a los españoles la estabilidad que nos ha faltado en la convivencia desde principios del siglo XIX, es menester actuar los mandatos constitucionales. Además, las fuerzas políticas que los concreten han de dar vida a las instituciones configuradoras del nuevo Estado democrático y deben asumir las funciones que éstas presuponen.

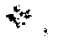

(21) Cfr. Vittorio Frosini, «Due forme di partecipazione», en Rivista Internazionale di Filosofia del Diritto, 1970 , págs. 68 y sigs.

(22) Gino Giuggni, "Stato sindacale, pansindacalismo, supplenza sindacale», en Il sindacato fra contratti e riforme (1969-1973). De Donato, Bari, 1973, págs. 35 y sigs. 